\title{
REPOBLACION DE TIERRAS ALICANTINAS POR JAIME I
}

\author{
Ramón Ferrer Navarro
}

La gran obra de reconquista y repoblación emprendida por Jaime I en el Reino de Valencia va a tomar nuevos rumbos a partir del año 1248. En efecto, si hasta entonces se había venido realizando la inserción de la población cristiana en el territorio valenciano sin crear grandes traumas en la musulmana, salvo en contadas excepciones; será en 1248 cuando el monarca tome una drástica resolución: expulsar a los musulmanes del Reino de Valencia.

¿Qué motivos tenía el Conquistador para tal decisión? Guichard señala como en su crónica Jaime I relata la motivación: la sublevación de Al-Azraq quien se apoderó rápidamente de varios castillos como los de Gallinera, Serra, Sagra, Pego, Penáguila, etc. (1).

El 6 de enero de 1248 se proclama la expulsión de los mudéjares valencianos; expulsión que minimizada por unos o exagerada por otros, habrá que dejar en su justo término, y este justo término nos indica que realmente fue importante en gran parte del reino y sobre todo se intenta que sea más afectiva en su frontera meridional, zona en la que se desenvolverá Al-Azraq dominando un extenso territorio hasta su definitiva rendición en 1258 .

El hecho de la expulsión de una parte de los mudéjares valencianos dará lugar a que el bienio de 1248-1249 se convierta en uno de los más

(1) GUICHARD, P., Nuestra Historia, vol. III, pags. 27-33. Valencia, 1980. 
importantes en cuanto a la concesión de donaciones a los nuevos pobladores cristianos para que de esta forma rellenen los huecos dejados por los musulmanes expulsados. Este aumento en el número de las donaciones efectuadas va a tener un especial significado por lo que se refiere a las tierras fronteras del sur; en efecto, esta zona es de vital interés para el monarca ya que ha de poner un freno a las actividades bélicas del caudillo sublevado, freno que sólo será posible si se rompe la estructura de la amplia población mudéjar de la zona y se la sustituye por cristiana.

El empeño pues de Jaime I de reprimir sublevaciones peligrosas en el sur del territorio, a la par que dotar a esta zona de una abundante población cristiana, se traduce en esas donaciones que concede a los que vienen a estas comarcas alicantinas y que a modo de flash recoge nuestro volumen segundo de los publicados sobre el "Libre del Repartiment".

¿Qué resultados se obtienen con la política de parcial expulsión y su sustitución por cristianos?, ¿cómo se traduce todo esto en tierras alicantinas? Vamos pues a intentar contestar a estos interrogantes a través del análisis que nos permite la documentación contenida en el citado Libre del Repartiment, referida a las comarcas de la Serranía de Alcoy, Marquesado de Denia, Valles de Pego y La Marina (2).

\section{LOS NUEVOS PROPIETARIOS}

El monarca aragonés comienza a repartir propiedades en estas comarcas citadas, fundamentalmente a lo largo del año 1249 , lo que se traducirá en la presencia, al menos como propietarios, de un buen número de cristianos, nuevos poseedores que alcanzan un total de 788 , cantidad que se reparte de la forma siguiente:

Para la Serranía de Alcoy hallamos a un total de 377 , a saber:

(2) La documentación utilizada procede exclusivamente de los registros del Libre del Repartiment del Regne de Valencia, vol. II, publicado por M. D. CABANES PECOURT y R. FERRER NAVARRO, Zaragoza, 1979 (en adelante Libre del Repartiment). 


$\begin{array}{lr}\text { Agres } & 5 \\ \text { Alcoy } & 40 \\ \text { Bocairente } & 232 \\ \text { Cocentaina } & 62 \\ \text { Muro } & 3 \\ \text { Penáguila } & 3 \\ \text { Perpuchent } & 20 \\ \text { Seta } & 8 \\ \text { Travadell } & 4 \\ \text { A la comarca del Marquesado de Denia van otros 13 que se distribu- } \\ \text { yen asi: } & 1 \\ \text { Alocayba } & 6 \\ \text { Denia } & 1 \\ \text { Negrals } & 1 \\ \text { Ondara } & 4 \\ \text { Pedreguer } & \\ \text { Para los Valles de Pego sumamos un total de } 69 . \\ \text { La Marina presenta otros } 329 \text { repartidos así: } \\ \text { Alaguar } & 24 \\ \text { Altea } & 40 \\ \text { Calpe } & 64 \\ \text { Callosa } & 55 \\ \text { Finestrat } & 20 \\ \text { Guadalest } & 82 \\ \text { Jalón } & 37 \\ \text { Polop } & 1 \\ \text { Segarria } & 1 \\ \text { Teulada } & 5 \\ & \end{array}$

A tenor de lo anotado, los 788 nuevos propietarios significan el gran interés por «normalizar» esta zona tan conflictiva por parte del monarca aragonés. ¿Qué puede indicar esta cifra de propietarios? En relación con los agraciados en todo el Reino de Valencia, los que corresponden a las comarcas alicantinas suman una proporción importante si pensamos que la penuria de repobladores ha sido una constante de la que sistemáticamente se lamenta el monarca y que para fechas más avanzadas no parecía superar los 30.000 en cálculo del propio Jaime I.

Cifra pues importante la alcanzada en estas comarcas meridionales del reino y que se reparten de forma diferente entre ellas mismas. La de los Valles de Alcoy - que cuenta con dos localidades situadas en lo 
que se ha venido en llamar "vía estratégica", Cocentaina, Alcoy (3)muestra un buen número de propietarios, alcanzando una media superior a la de muchas comarcas repobladas, si bien es cierto que gran parte de esa cantidad de propietarios lo son para Bocairente, quedando otros lugares, quizá más importantes, como Cocentaina y Alcoy, un tanto flojos.

Parecida es la conclusión que sacamos del análisis de los datos ofrecidos en la comarca de la Marina, comarca en la que tan importante será el dominio de Al-Azraq hasta su derrota en 1258; pues bien, en el corazón de la resistencia del caudillo musulmán (4), Jaime I ofrece propiedades que se reparten por toda la comarca, distribuidas por entre las numerosas alquerías que hallamos esparcidas a lo largo y a lo ancho de esta comarca y que en conjunto representan una presencia importante para casi todos los lugares.

Distinto es el cariz que hallamos para las comarcas de los Valles de Pego y del Marquesado de Denia; en el primer caso el reparto de propiedades no corresponde a muchos agraciados, así y todo no es despreciable la cifra alcanzada ni mucho menos, otro problema que no tratamos aquí es si permanecieron o no en estos lugares (5).

Por su parte, la comarca del Marquesado y para los lugares de Alocayba, Denia, Negrals, Ondara y Pedreguer, la documentación nos habla únicamente de 13 agraciados, cifra ínfima y que no puede responder en absoluto a la realidad; la única explicación, en la mayoría de quienes han tratado este tema, se debe a que el monarca encargó a Carroç el reparto de Denia y que las donaciones efectuadas por el señor de Rebollet, no fueron recogidas en lo que denominamos Libre del Repartiment, de ahí que apenas encontremos nada de estos donadios a la par que desconocemos la cuantía de lo efectuado por el almirante de Aragón (6).

¿Quiénes son y qué pueden representar como presuntos repobladores de estas comarcas los 788 propietarios cristianos? Parece claro pensar que si lo que pretende Jaime I es minar el poder de Al-Azraq y de sus secuaces en esta zona, lo lógico es que conceda donaciones a

(3) GUICHARD, P., Nuestra Historia, vol. III, pág. 32.

(4) GUICHARD, P., Nuestra Historia, vol. III, pág. 32.

(5) La posible no permanencia de los repobladores para esta zona es cuestionada por Guichard quien refiriéndose a los Valles de Pego dice: "el valle de Pego, donde no constan tierras ni pobladores cristianos antes de 1279-1280". GUICHARD, P., Nuestra Historia, vol. III, pág. 49. Ignoro la fuerza de esta afirmación.

(6) "En Denia no se conocen muchas donaciones pero quizá sea ello debido en parte al hecho de que era Carroç de Rebollet quien estaba encargado del reparto." Nuestra Historia, vol. III, pág. 49. 
quienes vayan a repoblar aquellas tierras e incluso, a ser posible que estén relacionados con el ejercicio de las armas. Hacer lo contrario, donar territorios en estas comarcas a personajes o instituciones que no aporten su presencia física, parecería algo que no casaría demasiado con la finalidad específica que representa un contenido único, radicalmente distinto al de otras comarcas situadas en otras partes del Reino.

El examen de la documentación nos muestra que las premisas que suponíamos debían presidir toda donación, en comarcas tan importantes para la estabilidad del Reino de Jaime I como son éstas, no siempre se cumplen, al menos en todas sus características; no existen concesiones a dignidades eclesiásticas ni a centros religiosos, eso es cierto, tampoco se conceden demasiadas donaciones a nobles que ciertamente no iban a residir en estos lugares por el hecho de poseer aquí algún bien, dado que contaban con una fortuna al margen de estas donaciones. La presencia del elemento nobiliario entre los recipendiarios de bienes es sin embargo más bien escasa y prácticamente se reduce a su presencia en la comarca del Marquesado de Denia; es aquí en donde se le concede al almirante Carroç unas rentas, mil besantes de plata (7), así como unas casas y un huerto (8). En la propia Denia se conceden igualmente bienes a otro noble de primera magnitud, don Ladron, a quien se le otorgan las casas de Mahomat Daryndal y los raales de Mahomat Dadabeix (9).

Otro personaje perteneciente a la nobleza es el de Eximinus Petri de Tirassona, ahora bien, no se trata en este caso de una donación propiamente dicha, sino más bien de una confirmación por parte del monarca de las propiedades que tiene este noble; entre las que se le confirman se hallan unas posesiones en Segarria, Sacra y Pego, posesiones que le vienen por compra realizada a lohanni Petri de Cuyllera (10); en realidad pues no es una donación.

(7) Libre del Repartiment, vol. I, asiento n. 819 . Carrocius: mille bisancios argenti in redditibus et exitibus de Denia per mare et per terram. Kalendas septembris. A este asiento no le damos validez ya que en el original aparece tachado $y$ anulado por sobrecargas claramente indicativas de que el texto ha sido invalidado. En nuestra edición lo insertamos entre paréntesis lo que indica asiento tachado.

(8) Carrocius: domos de Alcayt Aboabdile Avenmaymo, que sunt inter daraçanam et domos Çahem; et hortum de Hamo Abenbaca deb Alcohol et est inter ravallum et rapitam. Idus madii. Libre del Repartiment, vol. II, asiento n. 287.

(9) Dompnus Ladro: domos in Denia de Mahomat Daryndal et reallos de Mahomat Dadabeix Datum in Salent, bastita Xative, nonas madii. Libre del Repartiment, vol. II, asiento n. ${ }^{\circ} 286$.

(10) Per nos et nostros laudamus, concedimus et confirmamus vobis Eximinus Petri de Tirasona et vestris inperpetuum... et hereditatem quam a lohanne Petri de Cuyllera emistis in Sacra et in Segarria, et in Pego et fuit de Aveneziza, et...Datum Valentie, idus febroari anno MCCXLVIIII. Libre del Repartiment, vol. II, asiento n. ${ }^{\circ} 291$. 
Más dudoso es saber si pertenecen a la nobleza, y si se trasladaron a sus nuevas posesiones, dos sobrinos de Carroç, Andriolo y Alberto de Flix, quienes reciben 30 jovadas en el término de la actual población de Pedreguer; dado que ambos hermanos únicamente cuentan con esta donación en toda la documentación del Repartiment, no es de extrañar que sí se presentaran en la zona alicantina.

No resulta pues importante el número de beneficiados con donaciones que pertenecen a la nobleza por lo que, cuantitativamente - ya veremos por sus donaciones- no cabe esperar que desempeñen un papel primordial en la configuración tanto social como económica de la nueva sociedad formada por los propietarios cristianos.

Entre los nuevos poseedores de bienes abunda ese prototipo de hombre al que podemos denominar «hombre del común", y que en gran medida, en el caso que nos ocupa, estarán relacionados con el ejercicio de las armas; ahí tenemos los casos ya vistos para los valles de Alcoy: Martino de Hucles cum se decimo peditum (11); Simoni de Albalat cum XXX peditum (12); Iohanni de Naiara, Michaeli Arguixo et Dominico Lupi cum se duodecim ad caballum (13); o las profesiones de escudero y ballestero que encontramos entre los beneficiarios. Si bien en todos estos casos mencionados se podría pensar que quizá la entrega de propiedades pudiera estar relacionada con una especie de recompensa por los servicios prestados en el ejercicio de las armas, y que éste podría dar paso al gobierno de sus heredades una vez se les concediesen éstas; distinto es el caso de una donación que se hace no por los servicios prestados, sino por los que se están prestando; se trata de la concesión de 150 jovadas a treinta guardianes del "castrum" de Calpe (14). Con todo, y tras considerar el enorme peso específico que tienen los guerreros entre los nuevos propietarios de las comarcas alicantinas, no hay que pensar que todas las unidades de conquista se convierten en unidades de asentamiento (15) ya que de algunos de los que encabezan grupos de nuevos propietarios conocemos sus profesiones y estas nada tienen que ver con la milicia, se trata de horneros, pañeros, carniceros, costurera, etc.

(11) Libre del Repartiment, vol. II, asiento n. 1.298.

(12) Libre del Repartiment, vol, II, asiento n. ${ }^{\circ} 1.301$.

(13) Libre del Repartiment, vol. II, asiento $n .^{\circ} 1.061$.

(14) Libre del Repartiment, vol. II, asiento n. 1.045.

(15) FERRER NAVARRO, R., La repoblación de una comarca alicantina: la Serranía de Alcoy, en “Anales de la Universidad de Alicante. Historia Medieval», n. ${ }^{\circ}$, pág. 14. Alicante, 1982. 
En definitiva, por lo que se refiere a los propietarios nos hallamos con un apreciable número en relación con el total de los que hay en el resto del Reino de Valencia. Cifra importante y en la que no hay entidades ni jerarquías religiosas y apenas sí encontramos la presencia de la nobleza; básicamente este grupo de beneficiarios de las donaciones está compuesto por el "hombre del común", pertenecientes en buena medida a la milicia y en parte a las más variadas actividades.

\section{NATURALEZA DE LAS DONACIONES}

La zona que estamos analizando es a lo largo de 1249 y en años sucesivos un foco de conflictos por las sublevaciones mudéjares, de ahí el especial interés que Jaime I tiene por controlarla; control que se realiza a través de la naturaleza de las donaciones; es decir, siempre que éstas sean capaces de atraer a la escasa población cristiana dispuesta a situarse en estos centros conflictivos, máxime cuando coetáneamente en otras comarcas se están rellenando los huecos dejados por los mudéjares expulsados, y cuyo "relleno" no comporta el más mínimo peligro.

¿Cuáles son los bienes que se ofrecen en estas comarcas alicantinas?, ¿en qué cantidad se otorgan? Prescindiendo de un par de molinos y de unos réditos sobre la localidad de Denia - donación sobre la cual ya hemos comentado- la naturaleza de las donaciones versa sobre dos puntos fundamentales: la tierra y las casas.

Por lo que respecta a la tierra, las cantidades otorgadas son las siguientes:

\begin{tabular}{|c|c|c|c|c|c|}
\hline Lugar & Sece & cano & & Viña & Regadío \\
\hline Agres & 102 & $\mathrm{Ha}$. & & - & - \\
\hline Alcoy & 396 & Ha. & 1 & Ha. & - \\
\hline Bocairente & $2.122,5$ & $\mathrm{Ha}$. & 18 & $\mathrm{Ha}$. & - \\
\hline Cocentaina & 710,5 & Ha. & 16,5 & $\mathrm{Ha}$. & - \\
\hline Muro & 942 & $\mathrm{Ha}$. & & - & - \\
\hline Penáguila & 93 & $\mathrm{Ha}$. & & - & - \\
\hline Perpuchent & 186 & Ha. & & - & - \\
\hline Seta & 99 & $\mathrm{Ha}$. & & - & - \\
\hline Travadell & 21 & $\mathrm{Ha}$. & 6 & $\mathrm{Ha}$. & - \\
\hline
\end{tabular}

Para el Marquesado de Denia las tierras donadas son las siguientes:

\section{Alocayba}

Denia

Negrals

Ondara

Pedreguer
$21 \mathrm{Ha}$.

$63 \mathrm{Ha}$.

$18 \mathrm{Ha}$.

$12 \mathrm{Ha}$.

$41 \mathrm{Ha}$. 
La comarca de los Valles de Pego cuenta con:
Pego
$993 \mathrm{Ha}$.
80 haneg.

Por lo que respecta a la Marina tenemos:

$\begin{array}{lrrrcc}\text { Alaguar } & 342 & \mathrm{Ha} . & 1 & \mathrm{Ha} . & - \\ \text { Altea } & 486 & \mathrm{Ha} . & & - & - \\ \text { Calpe } & 819 & \mathrm{Ha} . & & - & - \\ \text { Callosa } & 546 & \mathrm{Ha} . & & - & - \\ \text { Finestrat } & 222 & \mathrm{Ha} . & & - & - \\ \text { Guadalest } & 939 & \mathrm{Ha} . & 165 & \mathrm{Ha} . & 55 \text { hanegadas } \\ \text { Jalón } & 540 & \mathrm{Ha} . & & - & - \\ \text { Polop } & 18 & \mathrm{Ha} . & & - & - \\ \text { Segarria } & 24 & \mathrm{Ha} . & & - & - \\ \text { Teulada } & 75 & \mathrm{Ha} . & & - & -\end{array}$

La tierra repartida en las respectivas comarcas alicantinas merece una serie de consideraciones, a saber: es importante cuantitativamente la concedida en la Marina, alcanzando una cifra igual a 4.181,5 hectáreas; por contra, lo ofrecido en los Valles de Pego sobrepasa ligeramente las 999 hectáreas, mientras que lo conocido para el Marquesado de Denia tan sólo llega a las 158 hectáreas. Del total de lo concedido, las 10.052 hectáreas, la tierra de secano representa nada menos que 9.832 hectáreas, o lo que es igual, el secano ocupa un $98 \%$ del total, proporción que se mantiene parecida en todos los lugares, con excepción de la Marina, en donde este tipo de terreno solamente ocupa el $96 \%$.

La viña, con sus 208,5 hectáreas representa un escaso $2 \%$; esta cantidad no está repartida entre todos los lugares de forma más o menos homogénea, ya que Guadalest absorbe prácticamente la totalidad con sus 165 hectáreas de viñedo. La huerta o regadío es casi inexistente dado que para la comarca de la Serranía de Alcoy la hallamos únicamente en Cocentaina (16), mientras que para el resto tan sólo existen 135 hanegadas, cantidad muy exigua en comparación al total.

¿Cómo se reparten estas 10.052 hectáreas entre los 788 beneficiarios? El tipo de sociedad que se establece en las comarcas alicantinas, si nos fijamos únicamente por las donaciones, no muestra una clara diferenciación, con excepción de la del Marquesado de Denia; así, la Serranía de Alcoy, la Marina y los Valles de Pego muestran unas oscilaciones similares que van de 3 a 5 jovadas, con excepción de Alaguar y

(16) Sobre este particular remito a mi artículo La repoblación de una comarca alicantina: la serrania de Alcoy, págs. 18-19. 
Guadalest en las que aparecen donaciones de 12 y 15 jovadas a un solo destinatario. El Marquesado de Denia presenta una estructura distinta ya que junto a las donaciones que contienen una superficie de tierra comparable a lo que hemos visto, existen otras, cuyos destinatarios son personajes de la nobleza a los que se les entregan rahales enteros, caso de Carroç (17), don Ladron, a quien se le concede el huerto que era propiedad de Mahomat Daryndal (18).

Los propietarios que surgen de estas donaciones, con las reducidísimas excepciones apuntadas, forman un cuerpo absolutamente mayoritario a favor de esos grupos a los que se les ha dotado entre 3 y 5 jovadas, con lo que la diferenciación social entre los agraciados por motivo de las nuevas propiedades no va a ser muy pronunciada.

Junto a la mayor o menor extensión de cada donadio, otro factor de primera magnitud para indicarnos el tipo de sociedad que se quiere establecer, es el de averiguar cómo se conceden estas propiedades: en alodio, con cargas, etc. (19). Del examen de la documentación observamos que las donaciones alodiales y las gravadas con cargas se mezclan y, al menos aparentemente, no hay nada que permita descifrar ef por qué unas se gravan y otras no. En la comarca de los Valles de Pego dos donaciones están gravadas con la carga de pagar los sueldos por cada jovada de secano y la correspondiente por hanegada de tierra de regadio: "pro unaquoque iovate $X$ solidis et pro orto ad rationem iovate» (20), lo que supone que están sometidas a impuesto un $79 \%$ de las tierras entregadas y un $65 \%$ de los propietarios. Igual carga hallamos para las donaciones en el Marquesado de Denia, la primera afecta a una propiedad en el término de Pedreguer y la segunda a otra en Gorgos (21). Para la comarca de la Serranía de Alcoy encontramos únicamente una donación gravada igualmente con los sueldos por jovada, situada en el término de Cocentaina, con una extensión de 145 jovadas

(17) Vid. nota 8.

(18) Vid. nota 9.

(19) La existencia de donaciones libres de cargas y donaciones gravadas con impuestos es algo que se alterna en nuestra documentación y que aparentemente no tiene explicación alguna. Veamos, por ejemplo, dos donaciones realizadas en la repoblación de Pedreguer. En la primera se nos dice: Bernardo Baster: domos in alcheria de Carracha, francas et liberas, que est in termino de Olocayba; et sex iovatas terre in eiusdem alcherie termino, unaqueque iovate pro $X$ solidis XIIII kalendas madii. Libre del Repartiment, vol. II asiento n. ${ }^{\circ}$ 1.071. En la segunda tenemos: Raymundo Dezortz: quasdam domos in Holocayba, scilicet in raal Abexanoch et $V$ iovatas terre contiguas eidem raalo. $V$ idus madii. Libre del Repartiment, vol. Il, asiento $n .^{\circ} 1.085$. Dos donaciones en idéntico lugar, una con carga económica $y$ otra libre.

(20) Libre del Repartiment, vol. II, asientos n. $1.070,1.095,1.349$ y 1.350

(21) Libre del Repartiment, vol. II, asientos $n .^{\circ} 1.105$ y 1.361 . 
y que afecta nada menos que a 30 propietarios (22). Caso contrario a lo tratado es el de la comarca de la Marina en la que todas las donaciones están exentas de cualquier tipo de gravamen.

En cuanto a las casas que se entregan tenemos:

\begin{tabular}{lcc}
\multicolumn{1}{c}{ Lugar } & $\begin{array}{c}\text { Número } \\
\text { de casas }\end{array}$ \\
\hline Agres & 5 \\
Alcoy & 32 \\
Bocairente & 1 \\
Cocentaina & 47 \\
Muro & - \\
Penáguila & - \\
Seta & - \\
Travadell & - \\
Alocayba & 1 \\
Denia & 4 \\
Negrals & - \\
Ondara & - \\
Pedreguer & 2 \\
Pego & 65 \\
Alaguar & 22 \\
Altea & - \\
Calpe & 20 \\
Callosa & 55 \\
Finestrat & 20 \\
Guadalest & 60 \\
Jalón & - \\
Polop & 1 \\
Segarria & 1 \\
Teulada & 5
\end{tabular}

De estas donaciones depende el concepto de repoblación que se quiera establecer; se podrá dar mayor o menor cantidad de tierra, o incluso sustituir ésta por otro beneficio cualquiera, pero lo que no puede faltar, para que se vaya a vivir al lugar indicado el nuevo repoblador, es la casa donde debe ubicarse. No hay pues lugar a dudas que

(22) Libre de/ Repartiment, vol. II, asiento n. 1.061. 
la vivienda, como componente de los bienes que reciben los repobladores, es una especie de termómetro que mide los grados de la realidad de la repoblación que se hace; si hay casas los nuevos propietarios pueden trasladarse alli donde han sido gratificados y nos hallamos ante una repoblación, en caso contrario son beneficiarios de tierras pero no van a vivir donde éstas están por lo que podemos hablar simplemente de propietarios de tierras pero no de repobladores.

¿Qué ocurre en las comarcas que estamos estudiando? La primera conclusión a la que podemos llegar partiendo del análisis que nos ofrece la entrega de casas es que no hay unas características similares para las cuatro comarcas; es más, podríamos indicar que se observan fuertes contrastes a la hora de evaluar las donaciones de viviendas, entre las localidades de una misma comarca y entre las varias comarcas. La Serranía de Alcoy muestra fuertes contrastes entre sus varias localidades, mientras Alcoy, Cocentaina y Agres presentan una buena proporción de donaciones que contienen casas, el resto no cuenta para nada con ellas por lo que de alguna manera son "subsidiarios" de otros lugares, tal es el caso de gente que tiene su casa en Cocentaina y sus tierras en Muro (23). El Marquesado de Denia cuenta con un número de donaciones referidas a viviendas que están dentro de lo que podríamos considerar como normal dentro de lo poco que sabemos para la repoblación de esta comarca. Mucho más densas en el tipo de bien que estamos comentando resultan las repoblaciones de los Valles de Pego y de la Marina. La primera de las dos muestra una fuerte proporción de donaciones que contienen tierra y casa: prácticamente la totalidad de los beneficiarios de donadios en estos lugares son dueños de tierras y casas por lo que la repoblación debería estar garantizada. Importante igualmente es la serie de casas concedidas a quienes van a repoblar la Marina, si bien aquí ya hay presupuestos distintos, dado que al lado de localidades como Alaguar, Callosa, Finestrat y Teulada, en las que todos los nuevos propietarios cuentan con casas, nos hallamos con Altea y Jalón, en las que no aparece la vivienda para nada en ninguno de los 77 nuevos agraciados, o los casos de Calpe y Guadalest, en donde la existencia de propietarios sin casa es bastante importante (24). El hecho de que Altea y Jalón no presenten la casa entre lo que se les entrega a los nuevos posesores, podría pensarse que se debe a un defecto de la documentación; en efecto, para esta zona y como caso

(23) FERRER NAVARRO, R., La repoblación de una comarca alicantina: la Serrania de A/coy. págs. 18-19.

(24) La proporción entre propietarios con casa y sin ella en las comarcas estudiadas es la siguiente: 
singular, algunas donaciones están duplicadas pero es una duplicidad un tanto especial, en la primera ocasión se señala la cantidad de tierra a repartir y en la segunda anotación se consigna, junto a todo lo apuntado en el otro asiento, la entrega de casas y si hay que pagar un censo por la tierra (25). Esto que se repite para varias localidades bien pudo pasar para Altea y Jalón.

\begin{tabular}{|c|c|c|}
\hline & Con casa & Sin casa \\
\hline \multicolumn{3}{|c|}{ Serranía de Alcoy } \\
\hline Agres & 5 & - \\
\hline Alcoy & 32 & 8 \\
\hline Bocairente & 1 & 134 \\
\hline Cocentaina & 47 & 16 \\
\hline Muro & - & 48 \\
\hline Penáguila & - & 3 \\
\hline Perpuchent & - & 20 \\
\hline Seta & - & 8 \\
\hline Travadell & - & 4 \\
\hline \multicolumn{3}{|c|}{ Marquesado de Denia } \\
\hline Alocayba & 1 & - \\
\hline Denia & 4 & 3 \\
\hline Negrals & - & 1 \\
\hline Ondara & - & 1 \\
\hline Pedreguer & 2 & 1 \\
\hline $\begin{array}{l}\text { Valles de Pego } \\
\text { Marina }\end{array}$ & 45 & 24 \\
\hline Alaguar & 22 & 3 \\
\hline Altea & - & 40 \\
\hline Calpe & 20 & 64 \\
\hline Callosa & 55 & - \\
\hline Finestrat & 5 & - \\
\hline Guadalest & 60 & 2 \\
\hline Jalón & 37 & - \\
\hline Polop & 1 & - \\
\hline Segarria & 1 & - \\
\hline Teulada & 5 & - \\
\hline \multirow{4}{*}{\multicolumn{3}{|c|}{ 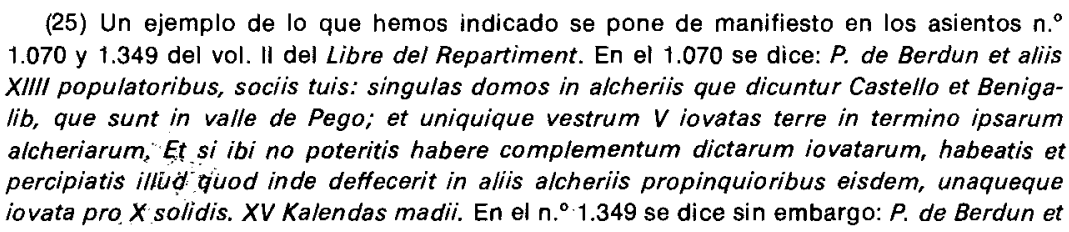 }} \\
\hline & & \\
\hline & & \\
\hline & & \\
\hline \multicolumn{3}{|c|}{$\begin{array}{l}\text { aliis XIIII populatoribus sociis suis: uniquique, } V \text { iovatas terre in alcheriis que dicuntur } \\
\text { Casteyllon et Benigalib. Et si ibi non habuerint complementum, residuum in alcheriis pro- } \\
\text { pinquioribus. XV kalendas madii. }\end{array}$} \\
\hline
\end{tabular}


Igualmente encontramos a faltar datos en lo referente a Calpe; de las 84 personas a las que se les ofrecen propiedades en esta localidad, tan sólo a 20 de ellas se les da una casa a cada uno, pero de estos 64 que no consta que se les diera viviendas, sabemos por la propia documentación lo siguiente: "R. Savassona, Maçot, P. Quarter, G. de Sespina, G. Despuy, A. de Savassona, Benedictus de Savassona et XXIII sociis custodientibus castrum de Calp: $V$ iovatas unicuique, et predictus R., l iovata in loco qui dicitur Merec, in termino de Calp, in alqueria que dicitur alqueria de Pertu de Calp, Albinen, Leusa, Lenes Benimaraix, Benimaglur et Canahor. XV kalendas septembris» (26). De su lectura hay que entender que se está refiriendo a treinta guardianes del lugar de Calpe, "custodientibus castrum de Calp", para los que se ofrece una cantidad de tierra pero no se habla para nada de casas ¿si están guardando el castro de Calpe como se dice, cómo no tienen casa? Habrá que pensar que estos guardianes tendrian con toda seguridad sus casas en el propio castro de Calpe, pero por lo que sea, la documentación no lo ha recogido; hecho este último que nos puede mostrar otras deficiencias en la documentación pero que no nos da patente para pensar que todos los repobladores de estas comarcas disponian de viviendas en el lugar en que se hallaban sus tierras.

Estas casas que se les otorga, ¿están en los núcleos de población o por el contrario se hallan en sus términos, en pequeños grupos de viviendas a los que denominamos Alquerías? En el primer caso se haIlan las entregadas en Agres, Denia, Callosa, Finestrat, Guadalest y Calpe; todas las viviendas están en los cascos urbanos de dichas poblaciones. Por contra las entregadas en los Valles de Pego, Alcoy, Alaguar, Teulada, Polop y Pedreguer, están todas en sus términos, en diversas alquerías: las de Barchata, Benehadal, Cota, Huxol en Alcoy; Castello, Benigalip, Benihayet, Huxola, Beniomeyr, Ceylen, Mernisa, Benigela, Raalhabelhabar, Benalbacar, Alcanicia y Benilacruci, en los Valles de Pego; Portella, Benimantel y Valug Exabech en Alaguar; Paratela en Teulada; Xirle en Polop; Carracha y Abenaxoch en Pedreguer. Un caso mixto es el que presenta Cocentaina ya que por un lado muestra donaciones de casas ubicadas en la población a la vez que por otro hay otras situadas en su término.

TRAS LA REPOBLACION, ¿HACIA UNA NUEVA SOCIEDAD?

Hemos hablado de un total de 788 propietarios a los que se les

(26) Libre del Repartiment, vol. II, asiento n. 1.045. 
asignan donaciones en estas comarcas alicantinas, donaciones que comprenden 10.052 hectáreas de tierra y 341 casas. Bien, estos propietarios inciden en un solo año, 1249, en la ocupación de casas y campos hasta entonces propiedad de musulmanes, ¿significa esto un cambio en la estructura de la sociedad o por el contrario hay una perduración de ella con asimilación por parte cristiana?

Para poder contestar a este interrogante habrá que partir del conocimiento de la sociedad islámica a la que se impone la cristiana. De entre los varios autores que tratan de la vida mudéjar, tales como Roca Traver, Burns, Guichard, etc., es este último quien dedica mayor atención a este problema. Según Guichard la sociedad musulmana anterior a la reconquista se caracteriza por ser una sociedad sin señores en el sentido occidental y feudal que comporta este término (27); se trata de una sociedad que se compone fundamentalmente de comunidades campesinas libres y casi con toda posibilidad propietarias de la mayor parte de la tierra (28).

Esta concepción mantenida en general para todo el territorio valenciano, Guichard la defiende igualmente de forma particular para las comarcas que estamos estudiando, ya que recientemente en un artículo sobre el norte de la actual provincia de Alicante, hace hincapié en la existencia en estas comarcas de fuertes comunidades rurales no "señorializadas" (29).

En resumidas cuentas, los repobladores cristianos van a encontrarse en la zona que estamos analizando con poderosas comunidades de campesinos que habitan en poblados rurales y que son propietarios de la mayor parte de la tierra y con una reducida porción de dominios particulares, propiedad de una clase rica de comerciantes, altos cargos políticos, administrativos y religiosos.

(27) «ll semble bien que la societé valencienne de l'epoque que précède immediatement la conquête chretienne des annees 1230-1245 puisse être considerée comme une societé sans seigneurs au sens occidental et feodal du terme, encore que de mot apparaisse parfais dans les descriptions qui sont faites de cette societé par les auteurs qui s'y sont interesses. GUICHARD, P., La société rura/e valencienne à l'epoque musulmane, en "Estudis d'historia agraria», n. 3 , pág. 51, Barcelona, 1979.

(28) "La societé valencienne anterieure a la conquête semble donc bien constituée principalment par des communautes rurales libres et selon toute probabilité proprietaires de la majeure partie de terres, soumisses seulement a une organisation etatique qui prélève une part de la production agricole sous la forme d'un impót dont la structure ne parait pas etre ecartée fondamentalment de la norme coranique." lgualmente: "au moment de la conquête chretienne, ces communautes rurales nous appraissent encore comme dotés d'une grande cohesion, et exerçent un plein droit de proprieté sur leurs terres". GUICHARD, P., La societé rurale valencienne a l'epoque musulmane, pág. 50.

(29) GUICHARD, P., Los castillos musulmanes de/ Norte de la Provincia de Alicante, en "Anales de la Universidad de Alicante. Historia Medieval", n. ${ }^{\circ} 1$, pág. 37. 
Sobre este tipo de sociedad hallamos las donaciones de 1249 que consagran a unos nuevos propietarios que penetran en el tejido social musulmán y que, al menos hipotéticamente, van a romperlo, Guichard habla de la reducida porción de dominios particulares, reducida porción que de alguna manera confirma la documentación por nosotros manejada; tal es el caso, por ejemplo, del cambio de uno de estos dominios particulares, propiedad de Mahomat Dadabeix, que va a manos de don Ladron; o las casas del alcayt Aboabdyle Avenmaymo y la finca o raal de Hamo Abenbaca que van a parar a Carroç (30).

Las propiedades de esa minoritaria clase rica musulmana parece que pasan íntegras a otra clase también minoritaria, la escasa nobleza aquí heredada; ahora bien, el resto de propietarios cristianos ¿ reciben las propiedades de los musulmanes sin alterarlas? Aun desconociendo la extensión que tendrían las propiedades de los campesinos musulmanes, no resulta muy aventurado pensar que con los repartos a los cristianos se cambiaría esto, y ello por algo tan simple como es la forma de realizarse el reparto de tierras en estas comarcas; aquí se coge a un grupo de repobladores, ya sean diez, veinte o cuarenta, y se les asignan tantos lotes de tierra como repobladores hay; estos lotes de tierra suelen tener de tres a cinco jovadas de extensión, por lo que nos hallaremos con una especie de cuadrículas de tierra que abarcan varias alquerías con lo que los linderos de los nuevos campos para nada semejarian a los anteriores. Dado que al repoblador que menos extensión se le da son 9 hectáreas ( 3 jovadas), ello supone una extensión muy superior al de la media europea, por lo que cabe pensar en una minoría de cristianos que al recibir sus propiedades desplaza a un número muy superior de musulmanes. Por otro lado, al recibir los cristianos en muchas ocasiones una casa junto con la tierra, y estas casas en su mayor parte están en las alquerías, lo que supondrá a su vez una nueva ruptura de las comunidades musulmanas que habitaban estas casas. Hay que pensar pues que si bien las minorías «nobiliarias", cristiana y musulmana, se pudieron suceder una a la otra cambiando únicamente de dueño los raales; por lo que se refiere al resto de los propietarios cristianos - sin lugar a dudas una minoría-, rompieron el tipo de sociedad establecido hasta entonces por la mayoría musulmana, por lo que estos musulmanes al perder sus campos y sus casas, unos emigrarían mientras que otros debieron entrar en contacto con los nuevos dueños de la tierra para trabajarla, ya fuese como mano de obra asalariada, ya como arrendatarios.

(30) Libre del Repartiment, vol. II, asiento 287. 
En resumen, del análisis de la documentación para esta zona meridional del Reino de Valencia, podemos indicar la intención del monarca de asentar en estas tierras a un grupo numeroso de repobladores cristianos, que con su presencia asegurasen una parcela del territorio valenciano que se veía amenazada por la sublevación de Al-Azraq; prueba de ello es la considerable cantidad de donaciones allí efectuadas en 1249 , así como la naturaleza de los nuevos propietarios, entre los que observamos nula participación de la Iglesia y más bien escasa de la nobleza, a la par que donaciones a colectivos, muchos de los cuales se componían de guerreros. Ahora bien, todo esto que parece confirmar la intención por parte de Jaime I de reforzar su presencia en estas tierras alicantinas, no concuerda con la naturaleza de las donaciones ya que si las comparamos con otras que se realizan en el mismo año para otros lugares del reino y que carecen del valor estratégico que le estamos suponiendo a las de las comarcas alicantinas resulta que son iguales o incluso superiores a las de las cuatro comarcas aquí analizadas, hecho éste que no acertamos a comprender. Si el sur del reino es peligroso por la actividad de la sublevación mudéjar y se quiere asentar pobladores cristianos, lo lógico es que se les atraiga con donaciones mejores que las que se ofrecen en el resto del territorio, ya que si uno puede optar entre tener unas propiedades en un lugar peligroso en 1249, como lo son las comarcas alicantinas, o por el contrario disponer de lo mismo en otros lugares sin peligro mudéjar, hecho que nos repite la documentación en innumerables casos (31), resulta evidente que la gente no iba a ir a la tierra alicantina.

(31) A la vez que se repueblan en 1249 las comarcas alicantinas, Jaime I concede donaciones en Peñíscola, Onda, Ahin, Eslida, Vall de Uxo, Segorbe, Jerica, Castellón, Sagunto, Segart, Gilet, Alfara, Algimia, Liria, Alcira, Carcer, Enova, Estubeny, Villanueva de Castellón, Cullera, Sueca, Corbera, etc. 